\section{María Concepción} Verona Martel

Dep. de Economia Financiera

y Contabilidad. Univ. de

Las Palmas de Gran Canaria

\section{José Juian}

Déniz Mayor

Dep. de Economia Financiera

y Contabilidad. Univ. de

Las Palmas de Gran Canaria

\section{REACCIÓN DEL MERCADO DE ACCIONES ESPAÑOL} ANTE ANUNCIOS DE CARÁCTER MEDIOAMBIENTAL: UNA APLICACIÓN DEL ESTUDIO DE EVENTOS $(*)$

Resumen.-Palabras clave.-Abstract.-Key Words.-1. Introducción.-

2. Revisión de la literatura.-3. Hipótesis de investigación.-

4. Aspectos metodológicos: 4.1. Selección de la muestra.

4.2. Diseño de la investigación.-5. Resultados empíricos y discusión:

5.1. Reacción del mercado ante anuncios negativos. 5.2. Reacción del mercado ante anuncios positivos. 5.3. Reacción del mercado a lo largo del tiempo.6. Conclusiones.-Bibliografía.-Anexo. Una selección de los anuncios analizados.

\title{
RESUMEN
}

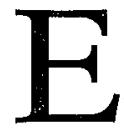

L propósito del presente estudio es explorar cómo valora el mercado de acciones español la gestión medioambiental de las empresas, bajo la hipótesis de que una reacción significativa del mismo ante determinados acontecimientos de carácter medioambiental consecuencia de la (in)acción corporativa es indicativa de que dicho mercado es sensible ante la problemática medioambiental. Tras analizar las noticias publi-

(*) Los autores agradecen las valiosas sugerencias y comentarios de dos evaluadores anónimos de la revista. 
cadas en la prensa periódica durante el período 1988-1998, alusivas a empresas relacionadas con impactos concretos sobre el medio ambiente, la conclusión más significativa es que nuestro mercado presenta una reacción débil ante las mismas, la cual, no obstante, es negativa ante los anuncios adversos para el medio ambiente y positiva frente a los anuncios de igual signo, siempre que, en este caso, no exista una vinculación con actividades que supongan una salida de fondos de la empresa.

\section{PALABRAS CLAVE}

Gestión medioambiental; Mercado bursátil; Contenido informativo.

\section{ABSTRACT}

The present study is aimed at exploring how the Spanish stock market values the environmental performance of the companies. We hypothesize that the fact that the market reacts significantly to certain environmental events caused by the corporate (in)action is an indication of the market awareness regarding environmental issues. After analysing the news published in the press during the period 1988-1998, which involve companies related to particular environmental events, we conclude that the market shows a weak reaction to environmentally related news. However, this response tends to be negative to adverse environmental news and positive to good environmentally news which do not imply funds outflow.

\section{KEY WORDS}

Environmental performance; Stock market; Information content.

\section{INTRODUCCIÓN}

El creciente número de siniestros industriales, así como el cierre de empresas por incumplimiento de la legislación ambiental puede provocar 
una sensación de riesgo que inhiba la inversión en sectores conflictivos, razón por la cual el inversor podría estar interesado en que la empresa llevase a cabo diversas medidas tendentes a la prevención, corrección o minimización del daño ambiental, bajo la presunción de que las compañías sin buenas prácticas medioambientales se verán cada vez más amenazadas. Así, algunas clases de inversores podrían estar ejerciendo un papel cada vez más importante en la realineación de la visión corporativa empresarial hacia prácticas respetuosas con el entorno. Es el caso de los denominados fondos de inversión verdes, creados bajo la filosofía de los fondos éticos (1) a fin de orientar la decisión de cartera, considerando no sólo el tradicional binomio rentabilidad-riesgo sino, además, la sensibilidad de los sujetos emisores de los títulos ante los asuntos medioambientales.

Algunos estudios, como el realizado por el World Business Council for Sustainable Development [1997], avalan tal planteamiento al mostrar cómo la mejora de la gestión medioambiental y la implementación del concepto de eco-eficiencia incrementa el valor para el accionista. En similar sentido se manifiestan Feldman, Soyka y Ameer [1997], quienes afirman que las inversiones en gestión medioambiental pueden ser costosas, pero cuando son evaluadas apropiadamente, se observa que muchas de estas inversiones pueden producir rendimientos positivos y sustanciales para la firma.

En general, tales consideraciones se apoyan en la hipótesis de que a largo plazo las actividades de reducción de la contaminación pueden traducirse en beneficios que contrarrestasen los efectos negativos del corto plazo, de forma que los desembolsos corporativos para prevenir, reducir o minimizar el daño ambiental favoreciesen en último extremo a la empresa y sus accionistas, gracias a la mejora en la productividad y la reducción de los costes por daño ambiental.

Cabe deducir, a sensu contrario, que aquellas empresas que se caracterizasen por una baja implicación en la protección del medio ambiente, con escasos o nulos desembolsos en dicha materia, pueden verse incapacitadas para adaptarse a los cambios del entorno, tanto regulativos como competitivos, acarreando consecuencias adversas para el patrimonio, si-

(1) Véase, por ejemplo, los trabajos de Suárez de Saro [1992], Camino [1993] y Camino y López [1995]. El fenómeno de la inversión selectiva data de los años vẹinte, cuando ciertas instituciones religiosas evitaban invertir en acciones "pecadoras" como las correspondientes a empresas conectadas con el alcohol y el tabaco [Skillius y Wennberg, 1998]. Véase, además, la Circular de 15 de noviembre de 1999 de la Comisión de Ética de INVERCO (elaborada a petición de la Comisión Nacional del Mercado de Valores) sobre utilización por las Instituciones de Inversión Colectiva de la denominacióni "ético», "ecológicoi o cualquier otra que incida en aspectos de responsabilidad social. 
tuación financiera y resultados de las compañías afectadas, y por tanto, siendo percibidas negativamente por los grupos de interés relacionados con ellas, en particular por los inversores. Bajo tales presunciones, parece razonable pensar que, dada la relación potencial entre la gestión medioambiental y los futuros flujos de caja de la empresa, la divulgación de información sobre la situación medioambiental de la empresa es susceptible de poseer contenido informativo para este último colectivo.

Dada la ausencia de trabajos sobre esta materia en nuestro país, el propósito del presente estudio es explorar cómo valora el mercado de acciones español la gestión medioambiental de las empresas que cotizan en Bolsa, bajo la hipótesis de que una reacción significativa del mismo ante determinados acontecimientos de carácter medioambiental consecuencia de la (in)acción corporativa es indicativo de que el mercado es sensible ante dicha problemática.

A tal efecto, en la siguiente sección se expone una revisión de la literatura sobre la materia. Las hipótesis de investigación propuestas se recogen en el tercer apartado. El proceso de selección de la muestra y la metodología utilizada se presenta en el apartado cuarto, mientras que los resultados obtenidos se comentan en la sección quinta. El trabajo finaliza con un resumen y conclusión del mismo.

\section{REVISIÓN DE LA LITERATURA}

Se han realizado diversos estudios que tratan de probar si la gestión llevada a cabo por la empresa en el campo medioambiental posee alguna repercusión en la valoración de ésta por los grupos de interés, destacando aquéllos que tratan de evaluar si la divulgación de las prácticas empresariales en dicho ámbito, así como de otra información de contenido medioambiental, tiene algún efecto en la cotización de los títulos en Bolsa, exponiéndose en el presente epígrafe varios de los trabajos más significativos.

Si bien autores como Giner [1992] sostienen que la información ambiental «es, vista con buenos ojos, tanto si la información la proporciona la empresa, como si el origen de la información es externo a ella», parece observarse que los resultados de los estudios realizados al objeto de contrastar tal afirmación tienden a ser inconsistentes y/o no concluyentes. Así, según algunos trabajos, la divulgación de información medioambiental podría arrojar efectos favorables sobre la cotización de los títulos, mientras que para otros, las consecuencias serían de signo adverso. 
Una de las vías para analizar el efecto de la actuación medioambiental corporativa sobre el precio de mercado de los títulos se apoya en los documentos que la empresa presenta ante los diferentes agentes económicos y sociales, observándose resultados contradictorios. Así, en el estudio realizado por Ingram [1978] se señala que no hay evidencia de que la divulgación de información por parte de las empresas sobre su responsabilidad social y medioambiental posea contenido informativo para los inversores. Sin embargo, según Anderson y Frankle [1980], la divulgación de datos de carácter social a través de las cuentas anuales tiene contenido informativo, siendo valorada positivamente por el mercado al no haber sido descontada previamente por los inversores, afirmándose además que los recursos económicos parecen estar asignados en el mercado a aquellas firmas que revelan información social. Asimismo, Freedman y Jaggi [1986] encontraron que la divulgación de información sobre contaminación por parte de empresas altamente contaminantes disminuía la percepción del riesgo sistemático por los inversores.

Como contrapunto a lo antedicho, Jaggi y Freedman [1992] estudiaron el impacto de la gestión de la contaminación sobre el valor de mercado y el resultado económico de la empresa, observando que la ratio precio-beneficio mostraba de forma destacada que los inversores valoraban peor a las firmas con una mejor gestión de la contaminación que a las más contaminantes, toda vez que la realización de fuertes desembolsos en actividades de protección medioambiental podría detraer recursos necesarios para las actividades de inversión consideradas productivas, provocando un impacto negativo sobre el resultado, así como sobre los flujos de tesorería a corto plazo.

Aunque la relevancia de la información medioambiental elaborada por la empresa, especialmente la de naturaleza contable, frente a otras fuentes de información es reconocida en estudios como los de Guthrie y Parker [1989], Deegan y Rankin [1997], y Adams, Hill y Roberts [1998], coincidimos con Roberts [1991] en que debe reconocerse que la exclusión de otras fuentes de información puede resultar en una representación algo incompleta de las prácticas de revelación.

En este sentido, se podría aducir que una de las limitaciones de la información medioambiental elaborada por la empresa, especialmente la de naturaleza contable, como medio para estudiar la reacción del mercado ante aquella, radicaría en que el posible efecto de la noticia fuese conocido previamente por el mercado. Por ello, otro posible enfoque de estudio podría sustentarse en el análisis de la reacción del precio de mercado de las acciones antes noticias medioambientales puntuales publicadas en otros medios como la prensa periódica. 
Siguiendo esta línea, en el trabajo de Shane y Spicer [1983] se muestra que las firmas analizadas experimentaron rendimientos negativos anormales relativamente elevados en los dos días inmediatamente anteriores a la publicación en la prensa de noticias sobre los informes realizados por el Council on Economic Priorities (CEP) sobre dichas compañías, siendo más negativos los rendimientos de las empresas con una peor gestión en el control de la contaminación. Según estos autores, esta reacción sería consistente con los cambios en la percepción de los inversores acerca de los futuros flujos de caja esperados en la fecha de publicación de tales estudios. En este sentido, cabría interpretar que dichos informes estarían anticipando la necesidad de realizar importantes inversiones futuras en el campo medioambiental.

A este respecto, Stevens [1984] analizó la reacción de los inversores ante la publicación por el CEP de información sobre los gastos que se preveía incurrir en el futuro para el control de la contaminación, dada su potencial relación con los flujos de caja futuros, observando que la difusión de tales datos poseía contenido informativo para los inversores, destacando la desfavorable reacción del mercado ante las noticias sobre empresas con probables desembolsos futuros de elevadas cuantías por dicho concepto, frente a la escasa respuesta en los casos de compañías con desembolsos previstos más reducidos.

Por su parte, Johnson, Mittelhammer y Blayney [1992] examinaron el comportamiento de los precios de las acciones de las compañías productoras de pesticidas en los Estados Unidos frente a determinadas actuaciones legislativas de la Administración sobre el sector, observándose que las noticias referidas a tales regulaciones repercuten de forma negativa y significativa sobre el valor de la firma en el mercado.

El efecto del accidente industrial de Union Carbide en Bophal (India) sobre el precio de los títulos de la propia empresa, así como sobre la cotización de las restantes compañías del sector químico, fue estudiado por Blacconiere y Patten [1994], comprobando que el mercado valoró negativamente dicho suceso, y que dicha reacción, aunque adversa, fue menor en aquellas empresas que habían realizado una mayor divulgación previa de datos ambientales, pudiendo interpretarse, en este caso, que los inversores consideraban que dichas compañías estaban haciendo frente a sus probables riesgos medioambientales de una mejor manera. Siguiendo un enfoque similar, Little, Muoghalu y Robinson [1995] estudiaron la relación entre el precio de las acciones y las noticias relativas a casos judiciales por deficiente gestión de residuos peligrosos, distinguiendo entre compañías que divulgaron información al respecto en sus estados contables y aquellas que no hicieron mención alguna, obteniéndose rendimientos 
anormales negativos en torno a la fecha de publicación en la prensa, siendo mayores en el caso de las empresas que no mostraron información alguna en sus cuentas anuales. Dichos autores concluyeron que tales noticias tenían contenido informativo, si bien su efecto podía ser mitigado si la empresa reconocía previamente la existencia del litigio.

Cabe citar finalmente a Klassen y McLaughlin [1996], quienes encontraron que los premios concedidos a las compañías por su destacada gestión medioambiental tenían un impacto positivo sobre la valoración de los títulos en el mercado de capitales.

\section{HIPÓTESIS DE INVESTIGACIÓN}

Un concepto íntimamente asociado a la problemática medioambiental es, precisamente, la noción de impacto ambiental, una de cuyas acepciones es la de alteración positiva o negativa producida en el medio ambiente como consecuencia, directa o indirecta, de la realización de una actividad humana, con respecto a la situación que existiría si tal actividad no se hubiese realizado (2).

Tal efecto o impacto se pone de manifiesto a través de la propia ocupación física del territorio, con el consiguiente desplazamiento de las especies originarias; por el consumo de materiales que pueden ser necesarios para el desenvolvimiento de otros seres; por la fabricación de productos, al liberar materias y/o formas de energía residuales al medio que pueden ser tanto beneficiosos como nocivos para otros agentes del sistema natural; así como por el cierre o clausura de la actividad.

A este respecto podemos preguntarnos, bajo la hipótesis de eficiencia del mercado, si en España tales impactos son lo suficientemente relevantes como para influir en la percepción de los inversores sobre el valor

(2) Bajo una óptica legal, el artículo 5. del Real Decreto $1131 / 1988$, de 30 de septiembre (BOE de 5 de octubre), por el que se aprueba el Reglamento para la ejecución del Real Decreto Legislativo de Evaluación de Impacto Ambiental, define el impacto ambiental como «los efectos que la ejecución de un determinado proyecto, obra o actividad causa sobre el medio ambiente». Para Conesa [1993], "hay impacto ambiental cuando una acción o actividad produce una alteración, favorable o desfavorable, en el medio o alguno de los componentes del medio. Esta acción puede ser un proyecto de ingeniería, un programa, un plan, una ley o una disposición administrativa con implicaciones ambientales».

En el contexto específico de la gestión ambiental corporativa, la norma UNE-EN ISO 14001: 1996, define el impacto medioambiental como "cualquier cambio en el medio ambiente, sea adverso o beneficioso, resultante en todo o en parte de las actividades, productos y servicios de una organización". 
bursátil de las acciones de la empresa causante de los mismos, dada su posible repercusión, detectada en los trabajos anteriormente citados, en los flujos de caja futuros de la empresa y su nivel de riesgo.

Como quiera que en algunos estudios realizados sobre cuentas anuales de empresas españolas que cotizan en Bolsa, como el de Moneva y Llena [1996], se destaca el hecho de que si bien las compañías suministran datos sobre aspectos relativos al medio ambiente, la información es escasa y genérica, haciéndose hincapié en las actuaciones positivas efectuadas, sin realizar mención alguna acerca de los efectos adversos sobre el medio, en el presente estudio se ha optado por analizar cómo influyen en la cotización de las acciones las noticias publicadas en la prensa diaria alusivas a impactos medioambientales causados por las empresas, tanto positivos como negativos.

Las diferentes actividades empresariales relacionadas con el medio ambiente pueden tener repercusiones de diverso signo sobre las compañías causantes de las mismas, tales como el logro o pérdida de accesos a mercados regulados por normas ambientales, la obtención de sentencias favorables o desfavorables en litigios por delito ecológico, posibles reducciones en los costes, etc. En este sentido, cabría cuestionarse si los inversores reaccionan en la misma dirección que el signo del hecho ambiental considerado, dada la posible existencia de un efecto diferenciado sobre la situación económico-financiera de la empresa.

Al objeto de evaluar tal premisa, en el presente estudio se realizó una distinción entre anuncios medioambientales positivos y negativos, siguiendo un enfoque similar al de Deegan y Gordon [1996], para quienes "las revelaciones positivas son definidas como información que presenta a la compañía operando en armonía con el entorno. Las revelaciones negativas son definidas como informaciones que presentan a la compañía operando en detrimento del medio ambiente». Así, definimos como anuncio medioambiental positivo aquel que recogiese un hecho o actividad referido a una empresa determinada y asociado a posibles impactos favorables en el medio ambiente. Por su parte, se consideraron como anuncios medioambientales negativos aquellos que aludiesen a hechos o actividades referidos a una empresa determinada y asociados a posibles impactos desfavorables en el medio ambiente. Partiendo de lo señalado, la primera hipótesis manejada en el trabajo es la siguiente:

H1: «El anuncio de que una empresa que cotiza en el mercado español de acciones está relacionada con un impacto concreto sobre el medio ambiente produce una reacción significativa en su precio de mercado del mismo signo que el del impacto». 
Otra variable a considerar es el «efecto patrimonial» de la noticia, ya que no necesariamente el signo de la noticia medioambiental ha de traducirse en una reacción homóloga en el precio de los títulos, dada la compleja relación existente entre la gestión económica general de la compañía y sus actividades medioambientales. En este sentido, Ullmann [1985] señala que es posible que el inversor reaccione adversamente tanto frente a las actuaciones empresariales medioambientalmente negativas (inversor ético) como ante aquellas otras que pudieran ser percibidas como actividades derrochadoras de recursos que no tienen una traducción favorable en los flujos de caja (inversor estilo Friedman), arguyendo, no obstante, que puede existir un nivel óptimo de gestión medioambiental que maximice o por lo menos no empeore los resultados de la gestión económica general de la compañía.

Bajo este enfoque y en el caso de las noticias que reflejan hechos positivos para el medio ambiente, nos hemos preguntado si el inversor discrimina entre aquellas que implican o implicarán una salida de fondos de la empresa, y aquellas otras que no poseen repercusión patrimonial inmediata, como es el caso de los premios, certificaciones, etc. Si bien a priori, un premio medioambiental sin valor pecuniario puede poseer un escaso o nulo valor patrimonial, podría ser percibido por el público como el resultado de una sólida gestión llevada a cabo en el pasado en dicho campo, existiendo la posibilidad de que dicha gestión se mantenga y que ello se traduzca en mayores ganancias futuras para la empresa [Klassen y Mclaughlin, 1996]. No hemos realizado dicha discriminación en el caso de los hechos medioambientalmente negativos ya que, por lo general, todos ellos suponen una probable salida de fondos de la compañía. La hipótesis planteada a este respecto es la siguiente:

H2: «El precio de mercado de una empresa relacionada con impactos medioambientalmente positivos reacciona de forma diferenciada en función de si tales impactos están asociados o no con salidas de fondos de la empresa».

Por otra parte, cabe cuestionarse si la respuesta de los inversores ante la publicación de noticias ambientalmente negativas podría ser diferente en función de la situación en que se halla la empresa debido a los problemas descritos en ellas, pudiendo distinguirse entre otras clases de noticias, la difusión de informes desfavorables, la presentación de denuncias ante los órganos competentes, la realización del correspondiente procedimiento judicial o administrativo, o la comunicación y/o ejecución de la sanción. A tal propósito, la hipótesis propuesta es la siguiente: 
H3: "El precio de mercado de una empresa relacionada con impactos medioambientalmente negativos reacciona de forma diferenciada según el contenido del anuncio publicado».

Finalmente, como quiera que el estudio abarca un período de once años, hemos considerado interesante analizar si se ha producido alguna variación en la percepción de los inversores acerca de los asuntos medioambientales, bajo la hipótesis de que con el transcurso del tiempo, dada la evidencia científica disponible así como la creciente conciencia social, los inversores valorarían cada vez más positivamente los eventos medioambientalmente positivos y, por el contrario, cada vez más negativamente los hechos medioambientalmente adversos, dando origen a la siguiente hipótesis:

H4: "Con el paso del tiempo, el precio de mercado de los títulos de las empresas reacciona con mayor intensidad ante el anuncio de un impacto medioambiental relacionado con las mismas".

\section{ASPECTOS METODOLÓGICOS}

\subsection{Selección DE LA MUESTRA}

Los anuncios que conforman la muestra están referidos a empresas que cotizan en el mercado de acciones español, siendo objeto de estudio el período 1988-1998. Dichos anuncios fueron extraídos de la base de datos de prensa BARATZ, mediante una búsqueda por empresas cotizadas, utilizando palabras claves como "medio ambiente», "impacto medioambiental» o "delito ecológico». Esta base contiene la información publicada en los medios escritos, tanto especializados en noticias económicas como de carácter general, tales como Expansión, Cinco Días, La Gaceta de los Negocios, El País o El Mundo. Las publicaciones de carácter semanal o mensual fueron excluidas al no coincidir su periodicidad con la información diaria generada por el mercado de acciones. Tampoco fueron estudiados los anuncios relativos a filiales poco significativas, bajo la premisa de que su efecto en la cotización de la empresa matriz sería escasamente relevante.

Si bien los mismos anuncios referidos a una sola compañía que fueron publicados el mismo, día en distintos medios se consideraban como uno solo, el problema surgía cuando la noticia aparecía repetida a lo largo de varios días o bien cuando se publicaban diferentes anuncios relati- 
vos a un mismo hecho distribuidos a lo largo del tiempo, ya que en estos casos cabría cuestionarse si se trataba de un mismo anuncio o de diferentes, aún no descontados por el mercado el primer día de su difusión (3). De acuerdo con la metodología de eventos, la solución propuesta ante este problema consistió en establecer un margen de varios días antes y después de la publicación de una noticia (en el presente estudio fue de 60 días) para considerar como «nuevo» el anuncio que sobre la misma materia se produjese fuera de dicho intervalo. Además, se observó que el número de anuncios coincidentes en fecha y referidos a distintas compañías era mínimo, analizándose en tal caso como un solo anuncio.

Finalmente, la relación de anuncios preseleccionados fue objeto de una depuración adicional consistente en la exclusión de los emitidos en fechas cercanas a otras noticias relativas a la empresa que pudieran afectar al precio de las acciones, no siendo posible determinar separadamente la contribución de cada uno de ellos al mismo, tales como anuncios de pago de dividendo, ampliaciones de capital o anuncios medioambientales de signo contrario. Asimismo, cabe destacar que los anuncios incluidos en la muestra se caracterizaron por su afectación a una empresa concreta y no a un sector.

A título ilustrativo, y de acuerdo con las premisas anteriormente establecidas, se consideraron como anuncios medioambientalmente positivos, entre otros, la inversión en activos dedicados a la prevención, corrección y/o minimización de daños al medio ambiente, la implantación de sistemas de gestión medioambiental, la obtención de una distinción medioambiental (EMAS, ISO 14000 , etc.), sentencias favorables o el archivo de litigios de carácter medioambiental. Se excluyó de esta categoría las noticias que recogiesen manifestaciones de defensa formuladas por los directivos de la compañía analizada o grupos de interés estrechamente vinculados a la misma ante acusaciones de daños al medio ambiente.

Por su parte, bajo la figura de los anuncios medioambientalmente negativos se recogieron, entre otros, las denuncias o acusaciones públicas de daños al.medio ambiente, las sentencias en firme por igual motivo o los informes técnicos adversos, con independencia del grado de vinculación que pueda existir entre la entidad emisora de los mismos y la compañía analizada. En el Anexo se muestran algunos ejemplos de anuncios seleccionados.

(3) Un caso típico es el de la denuncia por vía judicial de un daño al medio ambiente, que es seguida de la apertura de diligencias, el juicio, el fallo del tribunal, el posterior recurso de la sentencia, etc.; siendo todos y cada uno de dichos actos jurídicos objeto de publicación en prensa. 
El número total de anuncios positivos ascendió a 83 , de los cuales se excluyeron 42 por las razones expuestas, mientras que los anuncios negativos fueron 55, rechazándose 17 . No se incluye en el cómputo los anuncios calificados como repetidos. De esta forma, la muestra objeto de estudio quedó formada por 41 anuncios ambientalmente positivos y 38 negativos producidos en el período 1988-1998, correspondientes a empresas que cotizan en el mercado español de renta variable, cuya distribución temporal y por sectores se muestra en la Tabla 1.

De su lectura cabe reseñar que los sectores que generaron más anuncios positivos, antes de la correspondiente depuración, fueron, fundamentalmente, el eléctrico (45), el textil y papelero (15) y el químico y energético (13), caracterizados por su mayor conflictividad ambiental, al ser los que más noticias negativas generaron: 20 el textil y papelero, $14 \mathrm{el}$ eléctrico y 14 el químico y energético. Destaca la práctica ausencia de anuncios, tanto positivos como negativos, sobre empresas pertenecientes a sectores calificados de baja conflictividad en la materia.

Asimismo, se observa la existencia de un mayor número de anuncios positivos que negativos, que podría deberse, entre otras razones, a que los eventos medioambientales positivos son «realmente» más numerosos que los adversos; a la existencia de un eficaz sistema de control de la información por parte de la compañía afectada; a la vigencia de disposiciones legales que limiten el derecho a la información sobre sucesos medioambientales negativos (4); o, incluso, a la carencia de una mayor publicidad de las infracciones y sanciones dictadas por parte de los organismos reguladores (5). Finalmente, cabe resaltar el aumento de las noticias positivas a partir de 1993, un año después de la celebración de la Conferencia de Rio sobre el cambio climático.

(4) Véase, por ejemplo, el artículo 3 de la Ley 38/1995, de 12 de diciembre (BOE de 13 de diciembre), sobre el derecho de acceso a la información en materia de medio ambiente, en el que se establecen diferentes supuestos en los que las Administraciones Públicas podrán denegar la información sobre medio ambiente.

(5) Es paradigmático, en este sentido, el caso de la U.S. Environmental Protection Agency (EPA), que posee una base de datos en línea (http:/www.epa.gov/enviro/htmltris/ tris-query-java.html) fácilmente accesible al público que cubre cerca de 28.000 informes del Toxic Release Inventory (TRI). Al objeto de garantizar la fiabilidad de los datos, las compañías aludidas pueden efectuar las observaciones que estimen oportunas en el caso de que se produjesen errores en la información suministrada, así como realizar enlaces entre dicha base de datos y sus propias páginas web.

Apoyándose en el contenido de dicha base de datos, el Environmental Defense Fund's Chemical Scorecard Site publica una lista de los 20 principales contaminadores en cada uno de los Estados de la Unión, ofreciendo a las empresas la posibilidad de que expongan su versión de los hechos. 
TABLA 1

DISTRIBUCIÓN TEMPORAL Y POR SECTORE DE LOS ANUNCIOS QUE FORMAN LA MUESTRA

\begin{tabular}{|c|c|c|c|c|c|c|}
\hline & \multicolumn{3}{|c|}{ ANUNCIOS POSITINOS } & \multicolumn{3}{|c|}{ ANUNCIOS NEGATIVOS } \\
\hline Año & Sector & Total & Aceptados & Sector & Total & Aceptados \\
\hline 1988 & Textil y papelero & 1 & 1 & Eléctrico & 1 & 1 \\
\hline 1989 & Químico y energía & 1 & 0 & $\begin{array}{l}\text { Eléctrico } \\
\text { Químico y energía } \\
\text { Textil y papelero }\end{array}$ & $\begin{array}{l}1 \\
1 \\
1\end{array}$ & $\begin{array}{l}1 \\
1 \\
1\end{array}$ \\
\hline 1990 & $\begin{array}{l}\text { Eléctrico } \\
\text { Químico y energía }\end{array}$ & $\begin{array}{l}2 \\
2\end{array}$ & $\begin{array}{l}0 \\
1\end{array}$ & $\begin{array}{l}\text { Eléctrico } \\
\text { Textil y papelero }\end{array}$ & $\begin{array}{l}3 \\
3\end{array}$ & $\begin{array}{l}1 \\
3\end{array}$ \\
\hline 1991 & Eléctrico & 3 & 1 & $\begin{array}{l}\text { Cemento y construcción } \\
\text { Eléctrico } \\
\text { Textil y papelero }\end{array}$ & $\begin{array}{l}1 \\
2 \\
2\end{array}$ & $\begin{array}{l}1 \\
1 \\
2\end{array}$ \\
\hline 1992 & $\begin{array}{l}\text { Cemento y construcción } \\
\text { Eléctrico }\end{array}$ & $\begin{array}{l}1 \\
3\end{array}$ & $\begin{array}{l}0 \\
3\end{array}$ & $\begin{array}{l}\text { Eléctrico } \\
\text { Químico y energía } \\
\text { Textil y papelero }\end{array}$ & $\begin{array}{l}2 \\
1 \\
2\end{array}$ & $\begin{array}{l}2 \\
1 \\
1\end{array}$ \\
\hline 1993 & $\begin{array}{l}\text { Eléctrico } \\
\text { Minero-siderúrgico } \\
\text { Químico y energía } \\
\text { Textil y papelero }\end{array}$ & $\begin{array}{l}5 \\
1 \\
2 \\
2\end{array}$ & $\begin{array}{l}2 \\
0 \\
0 \\
2\end{array}$ & $\begin{array}{l}\text { Cemento y construcción } \\
\text { Eléctrico } \\
\text { Químico y energía } \\
\text { Textil y papelero }\end{array}$ & $\begin{array}{l}1 \\
1 \\
4 \\
2\end{array}$ & $\begin{array}{l}1 \\
0 \\
4 \\
2\end{array}$ \\
\hline 1994 & $\begin{array}{l}\text { Eléctrico } \\
\text { Químico y energía } \\
\text { Textil y papelero }\end{array}$ & $\begin{array}{l}7 \\
1 \\
2\end{array}$ & $\begin{array}{l}6 \\
1 \\
1\end{array}$ & Textil y papelero & 2 & 2 \\
\hline 1995 & $\begin{array}{l}\text { Automóvil } \\
\text { Eléctrico } \\
\text { Químico y energía } \\
\text { Textil y papelero }\end{array}$ & $\begin{array}{r}2 \\
11 \\
1 \\
2\end{array}$ & $\begin{array}{l}0 \\
7 \\
1 \\
0\end{array}$ & $\begin{array}{l}\text { Eléctrico } \\
\text { Textil y papelero }\end{array}$ & $\begin{array}{l}1 \\
1 \\
1\end{array}$ & $\begin{array}{l}0 \\
1 \\
1\end{array}$ \\
\hline 1996 & $\begin{array}{l}\text { Automóvil } \\
\text { Cemento y construcción } \\
\text { Eléctric } \\
\text { Otros servicios } \\
\text { Químico y energía } \\
\text { Textil y papelero }\end{array}$ & $\begin{array}{l}1 \\
1 \\
5 \\
1 \\
4 \\
6\end{array}$ & $\begin{array}{l}0 \\
1 \\
3 \\
0 \\
1 \\
3\end{array}$ & $\begin{array}{l}\text { Eléctrico } \\
\text { Químico y energía } \\
\text { Textil y papelero }\end{array}$ & $\begin{array}{l}3 \\
6 \\
3\end{array}$ & $\begin{array}{l}1 \\
1 \\
2\end{array}$ \\
\hline 1997 & $\begin{array}{l}\text { Cemento y construcción } \\
\text { Eléctrico } \\
\text { Químico y energía } \\
\text { Textil y papelero }\end{array}$ & $\begin{array}{l}1 \\
3 \\
2 \\
1\end{array}$ & $\begin{array}{l}1 \\
3 \\
1 \\
0\end{array}$ & $\begin{array}{l}\text { Químico y energía } \\
\text { Textil y papelero }\end{array}$ & $\begin{array}{l}1 \\
4\end{array}$ & $\begin{array}{l}1 \\
3\end{array}$ \\
\hline 1998 & $\begin{array}{l}\text { Automóvil } \\
\text { Bancos } \\
\text { Eléctrico } \\
\text { Químico y energía } \\
\text { Textil y papelero }\end{array}$ & $\begin{array}{l}1 \\
1 \\
6 \\
1 \\
1\end{array}$ & $\begin{array}{l}0 \\
0 \\
1 \\
0 \\
1 \\
\end{array}$ & Minero-siderúrgico & 5 & 3 \\
\hline & TOTAL & 83 & 41 & TOTAL & 55 & 38 \\
\hline
\end{tabular}

FUENTE: Elaboración propia a partir de las fuentes de información consultadas. 


\subsection{Diseño DE LA INVESTIGACIÓN}

La metodología propuesta tiene por objeto detectar si se producen rendimientos anormales significativos estadísticamente ante los anuncios sobre el comportamiento medioambiental empresarial a lo largo del período objeto de estudio.

El rendimiento anormal viene dado por la diferencia entre el rendimiento obtenido por un título en el mercado en un momento determinado (calculado a partir de los datos diarios de los precios en el mercado, sobre los cuales se realizan una serie de ajustes, por dividendos y por ampliaciones de capital, a fin de que ese dato refleje el rendimiento real del título) y el rendimiento esperado para dicho título en ese momento, estimado según el modelo de mercado, quedando la expresión siguiente:

$$
R A_{i t}=R_{i t}-\left(\alpha_{i}=\beta_{i} R_{m t}\right)
$$

donde,

$R A_{i t} \quad$ representa el rendimiento anormal del título $i$ en el momento $t$.

$R_{i t} \quad$ representa el rendimiento obtenido por el título $i$ en el momento $t$.

$R_{m t} \quad$ representa el rendimiento del mercado medido a través del Índice General de la Bolsa de Madrid en el momento $t$.

$\alpha_{i}$ y $\beta_{i}$ son los parámetros del modelo de mercado estimados por mínimos cuadrados ordinarios a lo largo de un período de 150 días, que abarca del día -160 al día -11, previos a la publicación de la noticia.

Los datos referentes a las cotizaciones diarias y al Índice General se han obtenido de la Bolsa de Madrid.

El período para observar si se producen rendimientos anormales es conocido con el nombre de ventana, seguido del número de días que abarca (ventana de 2 días, de 3 días, etc.), siendo el día 0 el momento en que el anuncio se publica en la prensa, centrándose nuestro análisis en las fechas más próximas al anuncio del evento. El uso de una ventana estrecha para analizar el efecto del acontecimiento, unido a la utilización de información diaria, reduce la probabilidad de que otro tipo de noticias, que pudieran distorsionar las conclusiones, estén incluidas en el efecto que se analiza.

$\mathrm{Al}$ objeto de determinar si la reacción del mercado ante los anuncios que se estudian es significativa en términos estadísticos, los rendimientos anormales estimados son sometidos a unas pruebas estadísticas, considerando como hipótesis nula que los rendimientos anormales son igua- 
les a cero. Para ello se ha utilizado el test estadístico no paramétrico de Corrado [1989], que se comporta como una distribución normal. Dicho test tiene igual poder y buena especificación que el test de Wilcoxon [Corrado, 1989], siendo recomendado por autores como Campbell y Wasley [1993] y Cowan y Sergeant. [1996].

El test de Corrado se apoya en la transformación de la serie temporal de rendimientos anormales obtenidos por cada título en sus respectivos rangos. Si denominamos $K_{i t}$ al rango del rendimiento anormal del título $i$, nos queda que:

$$
K_{i t}=\operatorname{rango}\left(R A_{i t}\right), \quad t=-160, \ldots,+10,
$$

considerando una serie temporal de 171 días (6), donde el rango $\left(K_{i t}\right)$ variará de 1 a 171, indicando el rango 1 el rendimiento anormal más pequeño; asignando un rango tanto a las rentabilidades anormales que componen el período de estimación como a las que componen el período que comprende la ventana. Para construir el estadístico, es necesario determinar el rango medio, definido por $\bar{K}$, el cual se calcula como $1 / 2$ más la mitad del número de rendimientos anormales considerados. El test de Corrado para el día 0 queda definido de la siguiente forma:

$$
Z=\frac{\frac{1}{N} \sum_{i=1}^{N}\left(K_{i 0}-\bar{K}\right)}{S(K)}
$$

siendo $N$ el número de anuncios o acontecimientos que componen la muestra para el día considerado, calculándose la desviación típica $(S(K))$ usando la muestra completa de 171 días.

El test de Corrado para analizar un período de más de un día, por ejemplo, la ventana formada por el intervalo $(a=+1, b=+2)$, vendrá dado por la siguiente expresión (7):

$$
Z=\frac{\frac{1}{N} \sum_{i=1}^{N} \sum_{t=a}^{b} \frac{\left(K_{i t}-\bar{K}\right)}{S(K)}}{\sqrt{b-a+1}}
$$

(6) Se ha considerado un período temporal de 171 días similar al utilizado por González y González [1997] que fue de 141 días (del día -130 al día +10), pero inferior al utilizado por Corrado que fue de 250 díás (del día -244 al día +5 ):

(7) Expresión recogida en el trabajo de González y González [1997], quienes aplican este test, ya que en el trabajo original de Corrado [1989] sólo se indica la fórmula para un día, no para un período de varios días. 


\section{RESULTADOS EMPÍRICOS Y DISCUSIÓN}

La Figura 1 muestra los rendimientos anormales acumulados generados en torno a la fecha de los anuncios objeto de estudio, distinguiendo, por una parte, los correspondientes a aquellos títulos de compañías sobre las que se publicaron noticias ambientalmente negativas y, por otra, los pertenecientes a empresas con noticias favorables. Destaca el comportamiento diferenciado de ambas series de datos tras la fecha del anuncio, evidenciado por la acusada tendencia decreciente experimentada en el precio de los títulos "negativos» frente al carácter aparentemente más estable de los títulos "positivos", que se traduce en la existencia de una brecha o desfase a partir del día +2 , con lo cual la noticia que se da a conocer tendría impacto en los precios de los títulos.

\section{FIgURA 1}

\section{RENDIMIENTOS ANORMALES ACUMULADOS EN TORNO A LA FECHA DEL ANUNCIO}

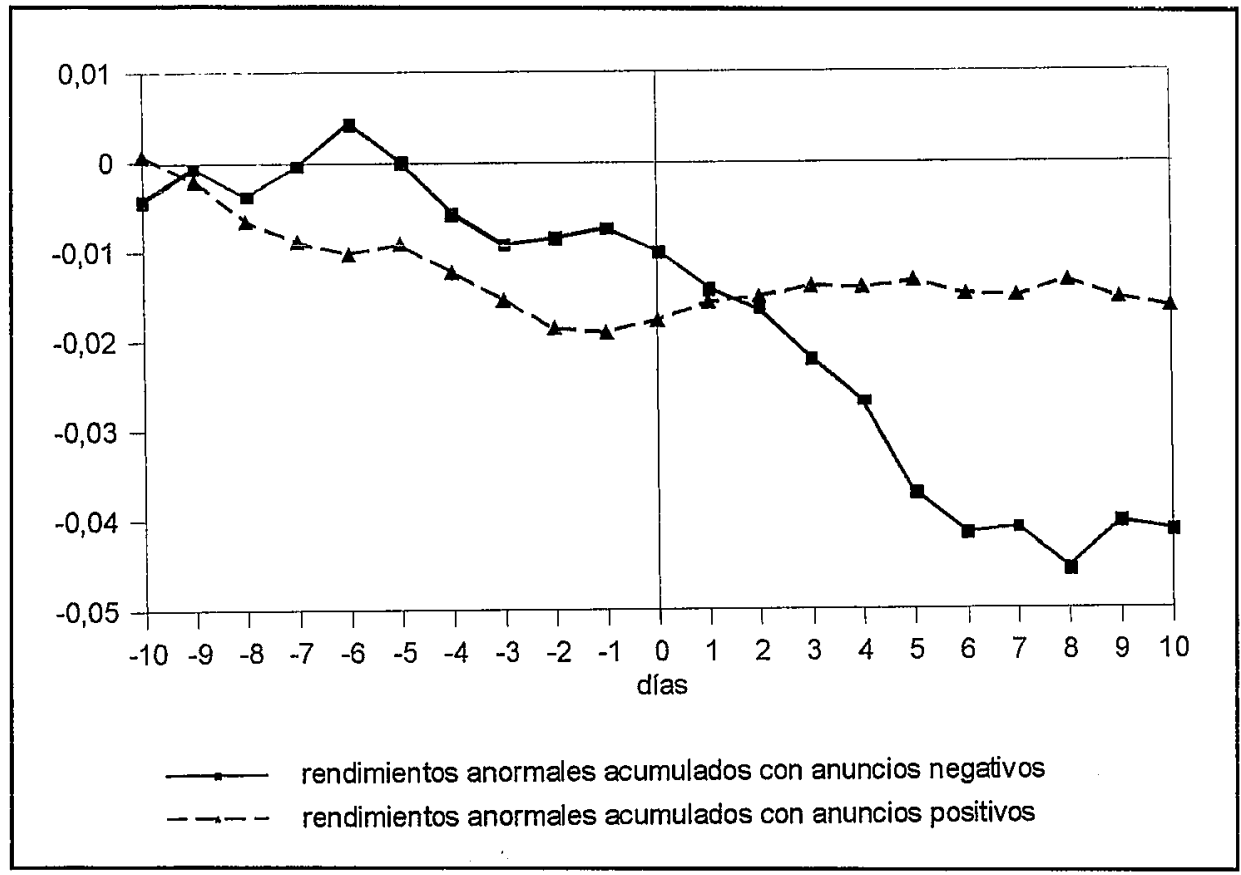

FueNTE: Elaboración propia. 
Obsérvese que el comportamiento de los datos en el intervalo $(0,+10)$ parece corresponderse con lo predicado en la primera hipótesis del presente estudio: la publicación de noticias ambientalmente negativas coincide con una bajada en el precio de los títulos afectados, mientras que los anuncios medioambientales positivos estarían asociados a reacciones de igual signo en el precio de mercado de los títulos considerados.

A fin de determinar si la reacción del mercado ante los anuncios estudiados es significativa en términos estadísticos, se aplicó el test de Corrado a la muestra seleccionada. En las líneas que siguen a continuación se estudian, en primer lugar, los resultados obtenidos en torno al efecto que los anuncios de carácter negativo tienen sobre el precio de mercado de las acciones, para proceder, posteriormente, a comentar el impacto que sobre los mismos tienen los anuncios de signo positivo, concluyendo el presente epígrafe, haciendo referencia a la evolución del comportamiento del mercado durante el período analizado ante los anuncios que conforman la muestra.

\subsection{REACCION DEL MERCADO ANTE ANUNCIOS NEGATIVOS}

En lo referente al estudio de la influencia de los anuncios medioambientales negativos sobre la cotización de las acciones, cabe destacar el hecho de que, tanto en el momento de su publicación en prensa como en gran parte de los días posteriores al mismo, los rendimientos anormales negativos son mayoritarios, siendo positivos la mitad de las veces en los días precedentes. El día de la publicación aproximadamente el 58 por 100 de los rendimientos anormales arrojó un valor negativo.

Como se observa en la Tabla 2, los resultados del test de Corrado muestran que tales rendimientos no son estadísticamente significativos en el momento de ser comunicado el evento. Asimismo, el estudio de la reacción conjunta acaecida entre la fecha del anuncio y los días anteriores y posteriores arroja similares resultados, salvo en la ventana $(0,+5)$, cuyos rendimientos anormales acumulados llegan a ser significativos sólo a un nivel de confianza del 90 por 100 .

Se puede afirmar, por un lado, que las noticias relativas a problemas medioambientales parecen ser interpretadas por el mercado de forma desfavorable, reflejándose tal percepción en una disminución del precio de las acciones de las empresas afectadas y, por otro, que dicha disminución no es lo suficientemente elevada para que resulte significativa estadísticamente, salvo en la ventana $(0,+5)$. 
TABLA 2

RESULTADOS OBTENIDOS CON ANUNCIOS NEGATIVOS $(n=38)$

\begin{tabular}{|c|c|c|c|}
\hline Dias & $\begin{array}{c}\text { Rendimientos } \\
\text { acumulados }\end{array}$ & Test de Corrado & $\begin{array}{c}\text { \% rendimientos } \\
\text { acumulados }<0\end{array}$ \\
\hline$(-10,-1)$ & $-0,0074$ & 1,3740 & 47,37 \\
$(-1,0)$ & $-0,0016$ & 0,2964 & 50 \\
0 & $-0,0026$ & $-1,0465$ & 57,89 \\
$(0,+1)$ & $-0,0068$ & $-1,1996$ & 63,16 \\
$(-1,+1)$ & $-0,0057$ & $-0,1332$ & 55,26 \\
$(0,+3)$ & $-0,0147$ & $-0,8060$ & 60,53 \\
$(0,+5)$ & $-0,0296$ & $-1,6982 *$ & 57,89 \\
$(+1,+10)$ & $-0,0312$ & $-1,5940$ & 50 \\
\hline
\end{tabular}

FUENTE: Elaboración propia.

* Estadísticamente significativo a un nivel de confianza del 90 por 100.

** Estadísticamente significativo a un nivel de confianza del 95 por 100

En la muestra se incluyen anuncios relativos al mismo hecho medioambiental, aunque en diferentes instantes del tiempo, por lo que cabría cuestionarse si sólo tendría contenido informativo el primer anuncio y no los restantes.

A tal objeto se analizaron las noticias que hacían referencia por primera vez a hechos medioambientalmente negativos, obteniéndose una muiestra de 26 anuncios. Los rendimientos anormales generados en las ventanas utilizadas en el presente trabajo fueron inferiores a los obtenidos con la muestra principal, no siendo significativos estadísticamente en ninguna de ellas. Así, en el momento 0 el rendimiento anormal es de $-0,0003$ (test de Corrado $=-0,1682$ ), mientras que en la ventana $(0,+5)$ fue de $-0,0242$ (test de Corrado $=-0,5889$ ), siendo en este caso negativo el 53 ' 85 por 100 de los rendimientos.

Si se estudia la muestra principal centrándose en la situación que se halla la empresa debido al problema ambiental que se comunica en cada uno de los anuncios considerados, se observa que la misma puede ser dividida en cuatro. La primera, formada por 8 anuncios correspondientes a empresas de los sectores químico (3), eléctrico (1), textil y papelero (3) y minero-siderúrgico (1), recoge todos aquellos informes desfavorábles, de procedencia tanto externa como interna; relativos a una empresa y su gestión en materia de medio ambiente, como por ejemplo, los informies de 
grupos ecologistas que ponen de manifiesto que una empresa ha realizado vertidos contaminantes. La segunda, compuesta por 9 anuncios relativos a empresas de los sectores eléctrico (4), textil y papelero (2), cementos y construcción (1) y químico (2), incluye las denuncias formuladas ante las autoridades competentes sobre empresas que no respetan el medio ambiente. La tercera, compuesta por 9 anuncios pertenecientes a empresas de los sectores eléctrico (1), textil y papelero (4), químico (2) y minero-siderúrgico (2), engloba aquellas noticias que hacen referencia al procedimiento administrativo o judicial abierto contra una empresa (por ejemplo, declaraciones de directivos ante los tribunales). Por último, la cuarta, integrada por 7 anuncios vinculados a empresas de los sectores cementos y construcción (1), textil y papelero (4), químico (1) y eléctrico (1), abarca las noticias referentes a las sanciones impuestas por daño ambiental. Debe aclararse que no necesariamente los mismos hechos son objeto de noticia en todas las categorías descritas, existiendo muchos casos que sólo son tratados en una de ellas y no en las demás. Los restantes anuncios contenidos en la muestra principal fueron excluidos de este nivel más detallado de análisis dada su heterogeneidad.

Como se observa en la Tabla 3, en el momento del anuncio el mercado reacciona de forma más fuerte ante eventos relacionados con procedimientos administrativos o judiciales, llegando a ser significativo a un nivel de confianza del 90 por 100, hecho que no sucede en las restantes muestras. Sin embargo, si se amplia la ventana al objeto de evaluar el comportamiento acumulado del mercado, se detecta en el intervalo $(0,+5)$ una reacción significativa tanto frente a los informes desfavorables como ante las sanciones, siendo más importante el primer caso, debido posiblemente a que las noticias relativas a las sanciones pueden haber sido parcialmente descontadas por el mercado en las fases previas del proceso. Otra posible explicación de tal respuesta es que el mercado haya estimado que la sanción recibida por la empresa es un "mal menor", considerando el abanico de penas que se le podría haber aplicado por el daño causado al medio natural. Cabe reseñar que la existencia de una respuesta desfavorable del mercado ante los litigios medioambientales coincide con los resultados obtenidos sobre tal cuestión por Little, Moughalu y Robinson [1995].

Por otra parte, la ausencia de una respuesta significativa del mercado frente a las denuncias presentadas ante la autoridad competente puede deberse a que no se consideren como hecho relevante hasta que el órgano decide iniciar el correspondiente procedimiento. No obstante, las conclusiones obtenidas deben ser adecuadamente ponderadas dado el pequeño tamaño de las miuestras analizadas. 
TABLA 3

RESULTADOS OBTENIDOS CON ANUNCIOS NEGATIVOS EN FUNCIÓN DEL TIPO DE NOTICIA

\begin{tabular}{|c|c|c|c|c|c|c|}
\hline & \multicolumn{3}{|c|}{ MUESTRA DE INFORMES DESFAVORABLES $(n=8)$} & \multicolumn{3}{|c|}{ MUESTRA DE DENUNCIAS $(n=9)$} \\
\hline Días & $\begin{array}{c}\text { Rendimientos } \\
\text { acumulados }\end{array}$ & Test de Corrado & $\begin{array}{l}\text { \% rendimientos } \\
\text { acumulados }<0\end{array}$ & $\begin{array}{c}\text { Rendimientos } \\
\text { acumulados }\end{array}$ & Test de Corrado & $\begin{array}{l}\text { \% rendimientos } \\
\text { acumulados }<0\end{array}$ \\
\hline $\begin{array}{c}(-10,-1) \\
(-1,0) \\
0 \\
(0,+1) \\
(-1,+1) \\
(0,+3) \\
(0,+5) \\
(+1,+10)\end{array}$ & $\begin{array}{l}-0,0386 \\
-0,0045 \\
-0,0076 \\
-0,0115 \\
-0,0083 \\
-0,0207 \\
-0,0626 \\
-0,0395\end{array}$ & $\begin{array}{l}-0,5058 \\
-0,9574 \\
-1,1133 \\
-0,9068 \\
-0,9956 \\
-0,5589 \\
-2,1401^{\circ} \div \\
-1,1698\end{array}$ & $\begin{array}{l}75 \\
62,5 \\
87,5 \\
75,5 \\
37,5 \\
75 \\
87,5 \\
62,5\end{array}$ & $\begin{array}{r}0,0185 \\
-0,0009 \\
-0,0010 \\
-0,0018 \\
-0,0017 \\
0,0023 \\
-0,0016 \\
0,0033\end{array}$ & $\begin{array}{c}2,2999 \\
-0,1819 \\
-0,1676 \\
-0,5050 \\
-0,7427 \\
0,0984 \\
0,0595 \\
0,0668\end{array}$ & $\begin{array}{l}33,33 \\
44,44 \\
55,56 \\
55,56 \\
66,67 \\
44,44 \\
33,33 \\
33,33\end{array}$ \\
\hline
\end{tabular}

\begin{tabular}{|c|c|c|c|c|c|c|}
\cline { 2 - 6 } \multicolumn{1}{c|}{} & \multicolumn{2}{c|}{ MUESTRA DE IPROCEDIMIENTOS EN CURSo $(n=9)$} & \multicolumn{3}{c|}{ MUESTRA DE SANCIONES $(n=7)$} \\
\hline Días & $\begin{array}{c}\text { Rendimientos } \\
\text { acumulados }\end{array}$ & Test de Corrado & $\begin{array}{c}\text { \% rendimientos } \\
\text { acumulados }<0\end{array}$ & $\begin{array}{c}\text { Rendimientos } \\
\text { acumulados }\end{array}$ & $\begin{array}{c}\text { Test de Corrado } \\
\text { acumdimientos } \\
\text { acumulados }<0\end{array}$ \\
\hline$(-10,-1)$ & 0,0140 & 1,1233 & 22,22 & $-0,0059$ & 0,9032 \\
$(-1,0)$ & $-0,0058$ & $-1,3750$ & 55,56 & $-0,0020$ & $-0,3322$ \\
0 & $-0,0128$ & $-1,7889 *$ & 66,67 & $-0,0023$ & $-0,5913$ \\
$(0,+1)$ & $-0,0043$ & $-0,8538$ & 77,78 & $-0,0094$ & $-0,9893$ \\
$(-1,+1)$ & 0,0026 & $-0,4018$ & 44,44 & $-0,0091$ & $-1,2592$ \\
$(0,+3)$ & 0,0039 & $-0,2843$ & 77,78 & $-0,0225$ & $-1,4323$ \\
$(0,+5)$ & $-0,0026$ & $-0,5138$ & 55,56 & $-0,0383$ & $-1,8596 *$ \\
$(+1,+10)$ & $-0,0199$ & $-0,9617$ & 55,56 & $-0,0433$ & $-1,1245$ \\
\hline
\end{tabular}

FUENTE: Elaboración propia. 


\subsection{REACCIÓN DEL MERCADO ANTE ANUNCIOS POSITIVOS}

En cuanto a los anuncios medioambientales positivos, se ha constatado que en los días anteriores a su publicación en prensa los rendimientos anormales diarios son negativos, pasando a positivos en la fecha del anuncio y los días posteriores. Tal y como muestra el gráfico de rendimientos anormales acumulados (Figura 1) para el período $(-10$, +10 ), parece observarse una mejoría o al menos estabilización en la tendencia seguida por los rendimientos anormales acumulados después del anuncio con respecto a la existente en el intervalo anterior al día 0.

Los resultados obtenidos al aplicar el test de Corrado (Tabla 4) muestran que existe una reacción favorable del mercado coincidente con la publicación de la noticia medioambiental positiva, llegando a ser estadísticamente significativa, a un nivel de confianza del 90 por 100 , sólo en el período $(0,+3)$, ventana cuyos rendimientos anormales acumulados positivos suponen casi el 54 por 100 del total, con lo cual la reacción del mercado ante el anuncio estaría extendiéndose a los días más próximos al momento de su publicación. Ahora bien, si se amplía el número de días comprendidos en la ventana, el valor del test no aumenta sino que comienza a disminuir. Por su parte, los resultados del análisis realizado con ventanas más amplias como $(-10,-1)$ y $(+1,+10)$ indican que la reacción acumulada del mercado en los días anteriores al momento 0

TABLA 4

RESULTADOS OBTENIDOS CON ANUNCIOS NEGATIVOS $(n=41)$

\begin{tabular}{|c|c|c|c|}
\hline Dias & $\begin{array}{c}\text { Rendimientos } \\
\text { acumulados }\end{array}$ & Test de Corrado & $\begin{array}{c}\text { \% rendimientos } \\
\text { acumulados }>0\end{array}$ \\
\hline$(-10,-1)$ & $-0,0190$ & $-2,0907^{* *}$ & 48,72 \\
$(-1,0)$ & 0,0009 & 0,9627 & 51,28 \\
0 & 0,0014 & 1,3539 & 51,28 \\
$(0,+1)$ & 0,0033 & 1,4520 & 48,72 \\
$(-1,+1)$ & 0,0029 & 1,1899 & 46,15 \\
$(0,+3)$ & 0,0052 & $1,8240^{*}$ & 53,85 \\
$(0,+5)$ & 0,0058 & 1,4371 & 61,54 \\
$(+1,+10)$ & 0,0014 & 0,0773 & 41,03 \\
\hline
\end{tabular}

FUENTE: Elaboración propia.

* Estadísticamente significativo a un nivel de confianza del 90 por 100.

** Estadísticamente significativo a un nivel de confianza del 95 por 100. 
es negativa, siendo además significativa a un nivel del 95 por 100, presentando un valor positivo para el conjunto de los días posteriores.

Por tanto, parece observarse una respuesta favorable del mercado ante los anuncios ambientalmente positivos, pero tal reacción no es lo suficientemente elevada para ser estadísticamente significativa, salvo en la ventana $(0,+3)$. El efecto favorable de las noticias medioambientales positivas sobre el precio de las acciones no parece extenderse de modo significativo más allá del día +3 , a diferencia de los anuncios negativos, cuya adversa influencia persistiría hasta el día +5 .

$\mathrm{Al}$ igual que se hizo con los anuncios negativos, de la muestra de anuncios medioambientalmente positivos se excluyeron todas aquellas noticias que hacían referencia a hechos que ya habían sido previamente difundidos, con el fin de que la muestra recogiera sólo las primeras noticias sobre un tema concreto; tras este proceso quedaron 32 anuncios. Los rendimientos anormales obtenidos, en general, para las distintas ventanas analizadas son menores, como es el caso del momento 0, que asciende a 0,0007 (test de Corrado $=0,8099$ ), o bien, bastante similares como ocurre en la ventana $(0,+3)$, con un rendimiento de 0,0055 donde sólo el $46^{\prime} 67$ por 100 de los mismos es positivo (test de Corrado $=1,2086$ ), no obteniéndose rendimientos anormales positivos significativos estadísticamente para otras ventanas.

A fin de contrastar la hipótesis de que, ante los anuncios medioambientales positivos, el inversor discrimina entre aquellas noticias alusivas a hechos que carecen de repercusión patrimonial inmediata y aquellas otras que reflejan una posible salida de fondos de la empresa, se descompuso la muestra de anuncios positivos en dos, denominadas respectivamente «muestra no financiera» y «muestra financiera».

Bajo la primera agrupación, integrada por 11 anuncios correspondientes a empresas de los sectores textil y papelero (3), eléctrico (6) y químico (2), se incluyeron certificaciones y premios no pecuniarios obtenidos, sentencias e informes técnicos favorables, etc. Su característica básica es que no suponen en el momento de la noticia o en el futuro una salida de fondos de la empresa. En el segundo grupo, formado por 20 anuncios pertenecientes a empresas de los sectores eléctrico (12), químico (2), textil y papelero (5) y cementos y construcción (1), se recogieron todas las actividades de inversión en activos de la compañía dedicados a la prevención, corrección o minimización de daños ambientales, así como declaraciones sobre la realización de futuras actividades medioambientales. Se excluyeron de este análisis los anuncios que incluían ambas clases de noticias, así como aquellas cuya atribución a una de las muestras establecidas no fue posible.

Tomando como base esta descomposición, en la Tabla 5 se muestra la existencia de un comportamiento contrapuesto en el mercado ante cada 


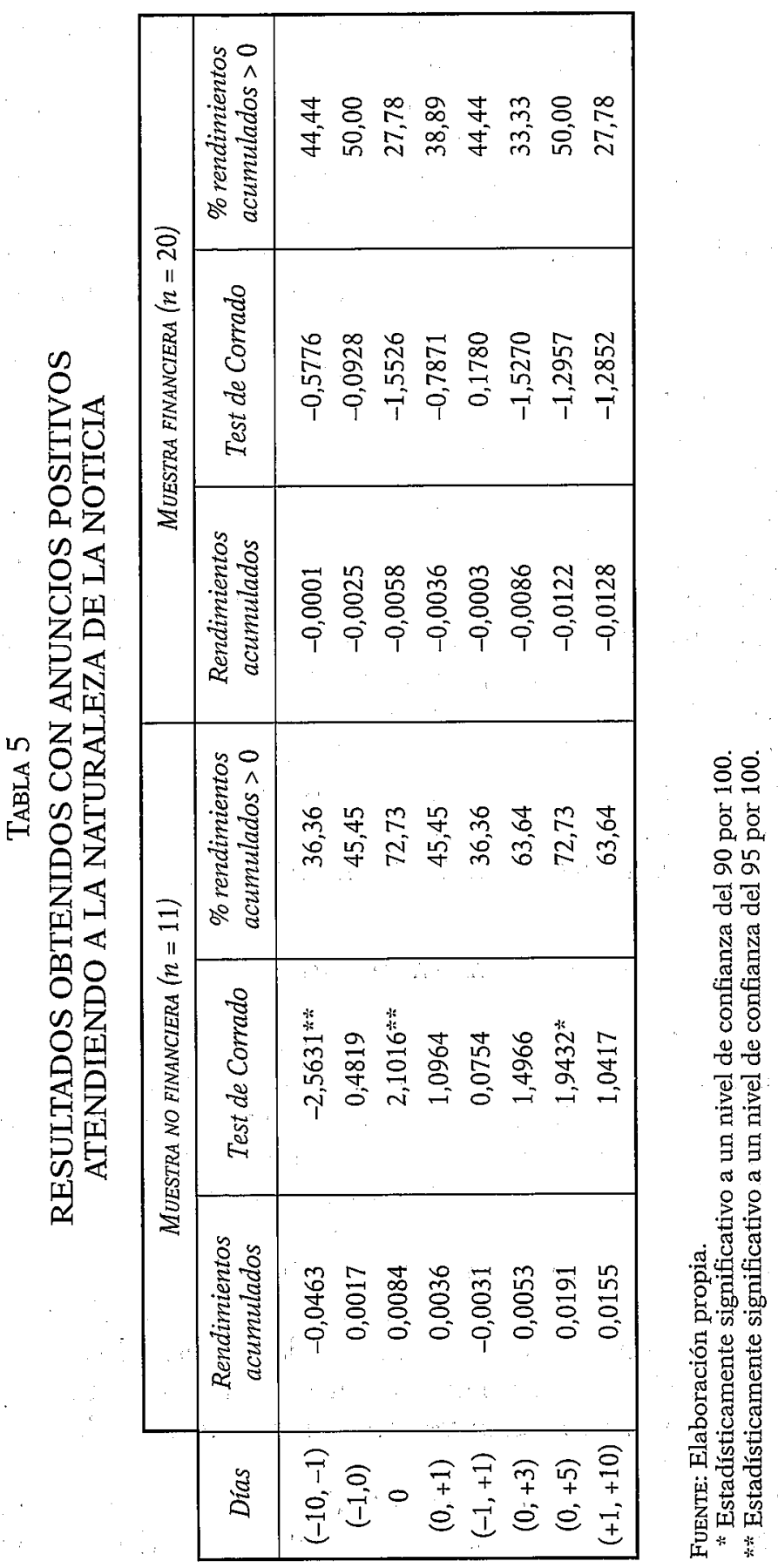


clase de noticia. Así, en el día 0 la publicación de eventos ambientalmente favorables de naturaleza no financiera da lugar a unos rendimientos anormales positivos, estadísticamente significativos a un nivel de confianza del 95 por 100, que representan el 73 por 100 del total para el día del anuncio. Una respuesta contraria se obtiene para ese mismo día en el caso de anuncios relativos a actividades de inversión medioambiental en la propia empresa, pues los rendimientos anormales positivos suponen tan sólo el 27,78 por 100 del total, no llegando a ser significativos estadísticamente.

Estos resultados coinciden con estudios como el de Stevens [1984] para las actividades de inversión medioambiental, así como con el de Klassen y McLaughlin [1996] para las noticias no financieras.

A la luz de lo señalado, cabe afirmar que no todos los eventos calificados como positivos para el medio ambiente son percibidos de igual forma por los inversores. En efecto, parece observarse que si bien el mercado valora favorablemente la obtención de premios, certificaciones, veredictos exculpatorios, etc. relacionados con las actuaciones medioambientales de la empresa, no ve de igual manera que la empresa destine recursos a la realización de inversiones dedicadas a la protección del medio ambiente, quizás por entender que ello supone una detracción de recursos que podrían ser destinados a actividades consideradas más productivas, lo que podría denotar una preeminencia de los inversores estilo Friedman, en la acepción de Ullmann [1985].

\subsection{REACCIÓN DEL MERCADO A LO LARGO DEL TIEMPO}

En 1992 se celebró la Conferencia de Rio, acontecimiento que gozó de una especial repercusión en los medios de comunicación, tanto nacionales como internacionales, generándose un importante debate en torno al problema del cambio climático, sus causas y sus consecuencias. Al abarcar el estudio el período 1988-1998, podemos preguntarnos si se ha producido alguna variación en lo que podría denominarse "sensibilidad" de los inversores ante los asuntos medioambientales, bajo la hipótesis de que con el transcurso del tiempo, dada la evidencia científica disponible así como la percepción social sobre la materia, los inversores valorarían cada vez más positivamente los eventos medioambientalmente positivos y, por el contrario, cada vez más negativamente los hechos ambientalmente adversos.

Por ello, tomando como punto de referencia el año de celebración de la Cumbre de Rio, se ha considerado interesante desagregar cada una de las 
muestras de anuncios, negativos y positivos, en dos, distinguiendo los producidos en el período 1988-1992, de los acaecidos en el período 1993-1998.

En relación con los anuncios negativos, los resultados obtenidos (Tabla 6) indican que se ha producido un ligero incremento en el número de anuncios después de 1992, produciéndose en el día 0 una respuesta del mercado más desfavorable ante tales acontecimientos en el período 1993-1998 que en el período 1988-1992. Sin embargo, en este período el mercado presenta una mayor reacción en los días próximos al momento del anuncio aunque no llega a ser significativa; en cambio en la ventana $(+1,+10)$ sí lo es para el período $1993-1998$, a un nivel de confianza del 90 por 100 . Cabe destacar no obstante, que existen diferencias en el tipo de noticia que predomina en cada período, pues en el primero la mayoría hace referencia a denuncias y en el segundo a procedimientos en curso, lo que contribuye a explicar el comportamiento del mercado. La diferencia entre las reacciones habidas en ambos períodos sólo es significativa (8) en el día +10 , a un nivel de confianza del 90 por 100 (test de Corrado $=1,6612$ ).

Al analizar los anuncios positivos, se observa que la diferencia entre los dos períodos analizados en el número de anuncios es más elevada que en el caso de los negativos, pues en los primeros 5 años objeto de estudio sólo se incluyen 6 anuncios, mientras que en los 6 años siguientes el número de anuncios incluidos se eleva a 35 . Al igual que en el caso anterior, los resultados (Tabla 7) indican que en el momento 0 la reacción favorable del mercado es mayor en el segundo período considerado. En el período 1988-1992, los rendimientos más elevados se obtienen después del día 0 , no siendo estadísticamente significativos, si bien estos resultados se deben estudiar con precaución dado el pequeño tamaño muestral. En este sentido, la diferencia entre las reacciones en ambos períodos sólo es significativa estadísticamente en la ventana $(0,+3)$, a un nivel de confianza del 90 por 100 (test de Corrado $=1,6713$ ). En cuanto al tipo de noticia predominante, en el primer intervalo tienen un peso más destacado las noticias de naturaleza financiera, estando en el segundo más igualado el porcentaje entre ambos tipos de noticia (financiera y no financiera). Este aumento de las noticias no financieras puede contribuir a explicar la respuesta del mercado, más significativa en términos estadísticos, en el segundo período.

(8) Para contrastar si las reacciones acaecidas en ambos períodios a lo largo de la ventana $(-10,+10)$ eran significativamente distintas, se aplicó el test de Corrado a las diferencias entre los rendimientos anormales diarios producidos en cada uno de los períodos considerados. 
TABLA 6

EL EFECTO DE LOS ANUNCIOS NEGATIVOS A LO LARGO DEL TIEMPO

\begin{tabular}{|c|c|c|c|c|c|c|}
\cline { 2 - 7 } \multicolumn{1}{c|}{} & \multicolumn{3}{c|}{ PERIOdo 1988-1992 $(n=16)$} & \multicolumn{3}{c|}{ PERiodo 1993-1998 $(n=22)$} \\
\hline Días & $\begin{array}{c}\text { Rendimientos } \\
\text { acumulados }\end{array}$ & Test de Corrado & $\begin{array}{c}\text { \% rendimientos } \\
\text { acumulados }<0\end{array}$ & $\begin{array}{c}\text { Rendimientos } \\
\text { acumulados }\end{array}$ & Test de Corrado & $\begin{array}{c}\text { \% rendimientos } \\
\text { acumulados }<0\end{array}$ \\
\hline$(-10,-1)$ & $-0,0109$ & 0,6857 & 56,25 & $-0,0048$ & 1,2248 & 40,91 \\
$(-1,0)$ & 0,0051 & 0,6877 & 31,25 & $-0,0064$ & $-0,4817$ & 63,64 \\
0 & 0,0013 & $-0,2446$ & 50,00 & $-0,0055$ & $-1,1370$ & 63,64 \\
$(0,+1)$ & $-0,0093$ & $-0,7745$ & 62,50 & $-0,0049$ & $-0,9399$ & 63,64 \\
$(-1,+1)$ & $-0,0055$ & $-0,1203$ & 50,00 & $-0,0059$ & $-0,5456$ & 59,09 \\
$(0,+3)$ & $-0,0226$ & $-0,1307$ & 50,00 & $-0,0090$ & $-0,9182$ & 68,18 \\
$(0,+5)$ & $-0,0372$ & $-1,1667$ & 50,00 & $-0,0241$ & $-1,2790$ & 63,64 \\
$(+1,+10)$ & $-0,0282$ & $-0,0721$ & 43,75 & $-0,0334$ & $-1,9529 *$ & 54,55 \\
\hline
\end{tabular}

FuENTE: Elaboración propia.

* Estadísticamente significativo a un nivel de confianza del 90 por 100.

** Estadísticamente significativo a un nivel de confianza del 95 por 100 


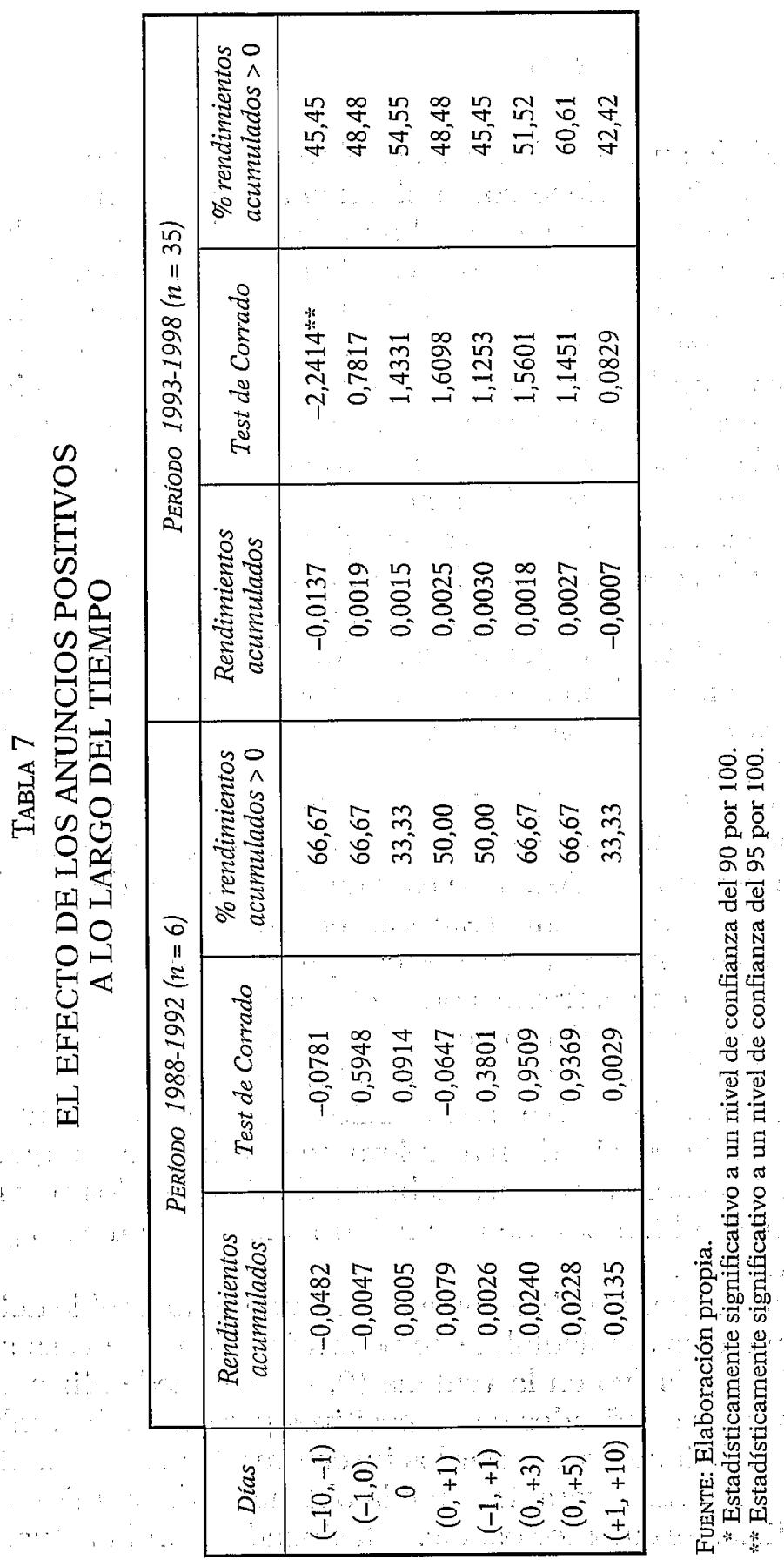




\section{CONCLUSIONES}

Dada la ausencia de trabajos sobre esta materia en nuestro país, el estudio realizado tiene como objetivo atisbar el grado de respuesta del mercado de acciones español ante las noticias publicadas en la prensa diaria nacional relacionadas con la gestión medioambiental de las empresas que cotizan en Bolsa, bajo la hipótesis de que la divulgación de las prácticas empresariales en torno a dicha materia posee contenido informativo para los inversores. De esta manera, una reacción significativa del mercado ante determinados acontecimientos de carácter medioambiental consecuencia de la (in)acción corporativa sería indicativa de que dicho mercado es sensible ante la problemática medioambiental.

De entre las principales conclusiones obtenidas para el período objeto de estudio, que abarca de 1988 a 1998, cabe destacar que, en general, las noticias negativas para el medio ambiente parecen ser interpretadas de forma desfavorable por el mercado, reflejándose tal percepción en una disminución del precio de las acciones de las empresas involucradas, si bien escasamente significativa en términos estadísticos, salvo en la ventana $(0,+5)$.

Un análisis más detallado de tales noticias muestra que la clase de evento descrito podría influir de forma diferenciada en la percepción de los inversores. Así, si se estudia el momento de la publicación de la noticia, se observa una reacción más fuerte y significativa del mercado ante los eventos relacionados con procedimientos administrativos o judiciales en curso, frente a otras clases de noticias. Ahora bien, si se evalúa el comportamiento acumulado del mercado, se observa una reacción significativa en el intervalo $(0,+5)$, tanto frente a la difusión de informes desfavorables sobre daños al medio, como ante los veredictos sancionadores, siendo más relevante el primer caso, quizás porque los anuncios sobre sanciones habían sido descontados previamente por el mercado o bien porque la sanción recibida fue menos grave de lo que se estimaba.

Aunque parece observarse una respuesta favorable del mercado ante los anuncios ambientalmente positivos, dada su escasa significatividad estadística (salvo en la ventana $(0,+3)$ se puede afirmar que no todos los eventos calificados como positivos para el medio ambiente son percibidos de igual forma por los inversores. En efecto, si bien el mercado parece valorar favorablemente la obtención de premios, certificaciones, veredictos exculpatorios, etc. relacionados con la actuación medioam- 
biental de la empresa, parece penalizar el hecho de que se dediquen fondos a la realización de inversiones dedicadas a la protección del medio ambiente, quizás por entender que ello supone una detracción de recursos que podrían ser destinados a actividades consideradas más productivas.

Asimismo, parece observarse una variación a lo largo del periodo analizado en lo que podríamos denominar «sensibilidad» de los inversores ante la problemática medioambiental dado que, aparentemente, en el día del anuncio el mercado de acciones en el período 1993-1998 valora mejor los eventos medioambientalmente positivos y peor los negativos, con respecto al período 1988-1992, manteniéndose esta tendencia para ventanas más amplias en el caso de los anuncios negativos.

A la luz de los resultados obtenidos cabe afirmar que en el mercado de acciones español comienza a existir una preocupación, aunque incipiente, acerca de las actividades empresariales que afectan al medio ambiente, basada en la presunción de que tales actividades pueden influir de modo relevante en los flujos de caja futuros de las compañías involucradas. No obstante, entendemos que deben realizarse estudios adicionales que repliquen tales asertos.

\section{BIBLIOGRAFÍA}

ADAMs, C. A.; HILl, W.-Y., y RoBeRTs, C. B. [1998]: «Corporate social reporting practices in Western Europe: Legitimating corporate behaviour?», British Accounting Review, vol. 20, n. ${ }^{\circ}$, March, pp. 1-21.

Anderson, J. C., y Frankie, A. W. [1980]: «Voluntary social reporting: An Iso-Beta portfolio analysis», The Accounting Review, vol. 45, n. ${ }^{\circ} 3$, July, pp. 467-478.

Biacconiere, W. G., y PAtTen, D. M. [1994]: «Environmental disclosures, regulatory costs, and changes in firm value», Joumal of Accounting and Economics, vol. 18, pp. 355-377.

Camino, D. [1993]: "Los fondos de inversión éticos», Revista Española de Financiación y Contabilidad, vol. 22, n. ${ }^{\circ} 75$, abril-julio, pp. 397-417.

Camino Blasco, D., y Lopez Pascual, J. [1995]: «Un análisis de la inversión ética en España», III Foro de Finanzas. Bilbao, 30 de noviembre y 1 de diciembre, pp. 1151-1170.

CAMPBELL, C. J., Y WASLEY, C. E. [1993]: «Measuring security price performance using daily NASDAQ returns», Journal of Financial Economics, vol. 33, pp. 7392.

CORRADO, C. J. [1989]: «A nonparametric test for abnormal security-price performance in event studies», Journal of Financial Economics, vol. 20, pp. 385-395. 
Cowan, A. R., y Sergeant, A. M. A. [1996]: "Trading frequency and event study test specification», Joumal of Banking \& Finance, vol. 20, n. ${ }^{\circ} 10$, pp. 17311757.

DeEgan, C., y Gordon, B. [1996]: «A study of the environmental disclosure practices of Australian corporations", Accounting and Business Research, vol. 26, n. ${ }^{\circ}$, pp. 187-199.

DeEgan, C., y RANKIN, M. [1997]: "The materiality of environmental information to users of annual reports", Accounting, Auditing and Accountability Journal, vol. 10, n. ${ }^{\circ} 4$, pp. 562-583.

Feldman, S. J.; SOYKA, P., y AMEer, P. [1997]: "Does improving a firm's environmental management system and environmental performance result in a higher stock price?" [en línea]. Environmental Group Study, ICF Kaiser International, Inc. January (citado el 30 de mayo de 1998). Disponible en World Wide Web: http:/www.icfkaiser.com/consulting/docs/Environ/resp_pays.htm.

Freedman, M., y JAGGI, B. [1986]: «Risk evaluation of firms disclosing pollution information in financial statements", Advances in Accounting, vol. 3, pp. 113125.

Giner Inchausti, B. [1992]: "Contabilidad y medio ambiente», Memoria de Ponencias y Comunicaciones, IV Congreso Nacional de Economía, Sevilla, pp. 664668.

González Méndez, V. M., y GonzÁlez Rodríguez, F. [1997]: «El efecto de los cambios en las calificaciones de rating sobre los precios de las acciones", XI Congreso Nacional y VII Congreso Hispano-Francés de la AEDEM, Lérida, 17-20 de junio.

Guthrie, J., y PARKer, L. D. [1989]: «Corporate social reporting: A rebuttal of Legitimacy Theory", Accounting and Business Research. vol. 19, n. ${ }^{\circ}$ 76, pp. 343352 .

INGRAM, R. W. [1978]: "An investigation of the information content of (certain) social responsability disclosure», Journal of Accounting Research, vol. 16, n. ${ }^{\circ}$ 2, pp. 270-285.

JAGGI, B., y FREEDMAN, M. [1992]: «An examination of the impact of pollution performance on economic and market performance: pulp and paper firms", Journal of Business Finance and Accounting, vol. 19, n. ${ }^{\circ}$, September, pp. 697-714.

Johnson, M. S.; Mittelhammer, R. C., y Blayney, D. P. [1992]: «Pesticide industry regulation: economic consecuences as revealed through stock price behaviour», Agrobusiness, vol. 8, n. ${ }^{\circ} 4$, 'pp. 347-364.

Klassen, Robert D., y McLaughlin, Curtis P. (1996): "The impact of environmental management on firm performances, Management Science, vol. 42, n. ${ }^{\circ}$, August;.pp. 119.9-1214.

Little, P.; Muoghalu, M. I., y Robinson, H. D. [1995]: "Hazardous waste lawsuits, financial disclosure, and investors' interests", Jourrial of Accounting, Auditing and Finance, vol. 10 , n ${ }^{\circ}$, pp. 383-400. 
Moneva Abadía, J. M., y Llena MacarRulla, F. [1996]: «La información medioambiental publicada en los informes anuales de las grandes empresas españolas», Ponencia y comunicaciones sobre Contabilidad Financiera. VII Encuentro de Profesores Universitarios de Contabilidad, Barcelona, 5-8 de junio, .pp 417-436.

RoBERTS, C. B. [1991]: «Environmental disclosures: A note on reporting practices in Mainland Europe», Accounting, Auditing and Accountability Journal, vol. 4, n. 3 , pp. $62-71$.

SHANE, P. B., y SPICER, B. H. [1983]: «Market response to environmental information produced outside the firm", The Accounting Review, vol. 48, n. ${ }^{\circ}$, July, pp. 521-538.

SKri.mus, Å., y WennBerg, U. [1998]: Continuity, Credibility and Comparability. Key challenges for corporate environmental performance measurement and communication. Report commissioned by the European Environmental Agency, February, $85 \mathrm{pp}$.

StEVENS, W. S. [1984]: «Market reaction to corporate environmental performancen, Advances in Accounting, vol. 1, pp. 41-61.

SUÁREZ DE SARO, J. M. [1992]: «Fondos especializados: la biotecnología y el medio ambiente», Estrategia Financiera, n. ${ }^{\circ} 73$, abril, pp. 16-20.

UlLmanN, A. A. [1985]: "Data in Search of a Theory. A Critical Examination of the Relationship Among Social Performance, Social Disclosure and Economic Performance in U.S. Firms", Academy of Management Review, vol. 10, n. ${ }^{\circ}$, pp. 540-557.

World Business Council For Sustainable Development; Blumberg, J.; Korsvold, $\AA$., y BLum, G. [1997]: Environmental performance and shareholder value, WBCSD, Geneva, May.

\section{ANEXo}

\section{UNA SELECCIÓN DE LOS ANUNCIOS ANALIZADOS}

Noticia medioambiental positiva financiera

Periódico: Expansión.

Fecha: 12 de enero de 1996.

Título: «Breves: Varios»,

Resumen: La Refinería de Ertoil en el complejo petroquímico de La Rábida, propiedad del grupo CEPSA y ubicada en Palos, Huelva, invertirá 5.860 millones en la puesta en funcionamiento, antes de final de año, de dos nuevas plantas de mejora medioambiental de su proceso productivo. 
Noticia medioambiental positiva no financiera

Periódico: Cinco Días.

Fecha: 29 de julio de 1994.

Título: «Retirada la querella por delito ecológico a ENDESA».

Resumen: Los alcaldes de 27 municipios de las comarcas castellonenses de Els Ports y El Maestrazgo firmaron el pasado miércoles en el Juzgado de Alcañiz, Teruel, la retirada de la querella criminal por presunto delito ecológico contra cuatro directivos de la Empresa Nacional de Electricidad, ENDESA, entre ellos su presidente, Feliciano Fuster.

Noticia medioambiental negativa por informe desfavorable

Periódico: El País.

Fecha: 13 de junio de 1998 .

Título: «El CSN asocia la radiactividad de chatarra en una acería de Algeciras con la detección de cesio en Europa».

Resumen: El Consejo de Seguridad Nuclear sospecha que el incremento de cesio 137 detectado en varias estaciones radiológicas europeas podría tener su foco emisor en un producto quemado en los hornos que la acería Acerinox posee en Algeciras (Cádiz).

\section{Noticia medioambiental negativa por denuncia}

Periódico: Cinco Días.

Fecha: 2 de marzo de 1991.

Título: «La Comunidad de Madrid se querellará contra Portland».

Resumen: El Consejo de Gobierno de la Comunidad de Madrid aprobó la interposición de una querella contra la empresa Portland Valderribas por considerar que la factoría El Alto, de su propiedad, ha cometido un delito ecológico contra la salud pública y el patrimonio al incumplir la normativa sobre protección de medio ambiente y provocar, directa o indirectamente, vertidos peligrosos para la salud.

Noticia medioambiental negativa por procedimiento administrativo o judicial en curso

Periódico: La Voz de Galicia.

Fecha: 29 de abril de 1996.

Título: «El fiscal del caso ENCE busca testigos claves sobre la toxicidad de sus gases».

Resumen: El fiscal jefe de la Audiencia de Pontevedra busca testigos en el caso ENCE sobre la toxicidad de sus gases, compuestos de azufre y mercaptanos, y la peligrosidad de sus vertidos de mercurio y sus derivados, a causa de los posibles fallos en los sistemas de seguridad de la empresa.

Noticia medioambiental negativa por sanción

Periódico: Cinco Días.

Fecha: 18 de abril de 1997. 
Título: "La Audiencia de Zaragoza eleva las penas a los directivos de Sarrió». Resumen: La Audiencia Provincial de Zaragoza desestima los recursos de apelación interpuestos por los directivos del grupo papelero Sarrió y Celulosa, S.A., condenados como autores de un delito contra el medio ambiente. El tribunal aumenta las penas de cárcel a los directivos y eleva las cuantías de las multas e indemnizaciones. 
